\title{
RELATIONSHIP BETWEEN HYDROBIOLOGICAL AND HYDROCHEMICAL PARAMETERS OF LAKES OF KARELIA AS INFLUENCED BY THEIR GEOECOLOGICAL CHARACTERISTICS
}

\author{
N.M. Kalinkina \\ Northern Water Problems Institute of Karelian Research Center of \\ the Russian Academy of Science \\ Pr A. Nevskogo, 50, Petrozavodsk, 185030, Russia \\ Ph.: 8(8142)576520, fax: 8(8142)578464, e-mail: kalina@nwpi.krc.karelia.ru
}

\begin{abstract}
On the data on 110 lakes of Karelia the role of natural and anthropogenic factors in the forming of hydrochemical and hydrobiological regimes is discussed. It is shown that the prognoses of hydrobiological parameters on the base of hydrochemical data using regression analyses is not possible due to high variability of data. For the purpose of reconstruction hydrobiological data the complex indexes were worked, then the classification of lakes of Karelia was done. Using the methods of multivariate statistics and the contingency tables the connections between chemical and hydrobiological parameters were investigated. The prognoses tables were calculated to reconstruct the zooplankton and zoobenthos biomass on the base of total phosphorous concentration. The precision of the prognoses varied within 55-86\%.
\end{abstract}

Keywords: lakes of Karelia, hydrochemical and hydrobiological data, regression analyses, contingency tables, prognosis.

\section{Introduction}

One of the major tasks for hydroecology is assessment of the bioresource potential of waterbodies. The dynamic state of aquatic ecosystems, their heterogeneity, the impossibility to survey the whole waterbody make this task very complex. Lack of information about the biological resources of lakes poses the task of reconstructing them using expert information systems $[2,4]$.

The study objects in our research were lakes of Karelia. The climate predetermines their distinctive features (short growing season, fairly low temperature in summer, high precipitation in the catchment, high percent cover of wetlands in the catchment), and the underlying rock geology (slight weathering of mineral components from basic rocks). This, in turn, tells on the hydrological regime (high flowage) and water chemical composition (very low content of mineral substances in the water, low nutrient concentrations; low $\mathrm{pH}$, elevated humic matter content). The action of the climatic and the geological factors results in low productivity of the aquatic ecosystems. Geoecological characteristics of the water ecosystems of Karelia should be taken into account in reconstruction of the missing hydrobiological data from available indices.

The aim of the present study is to investigate the relationship between hydroecological parameters of lakes of Karelia, and to work out a technique for reconstructing hydrobiological data using hydrochemical indices.

\section{Materials and methods}

The input material in the study was archival data on 110 lakes available from the Northern Water Problems Institute (total phosphorus, suspended matter, chlorophyll "a", zooplankton and benthos biomass). The data were obtained in the period 1960-2008. The most of the hydrochemical data were calculated as an average values for the summer season. The samples of water were processed according to standard methods which were described in the Guide [6]. The hydrobiological data were collected mainly in July-August. 
The data were mathematically processed using multivariate statistics methods: correlation, regression, cluster analyses, as well as nonparametric criteria - Spearman's rank correlation coefficient $[1,3,5]$.

\section{Results and discussion}

To forecast the parameters at the first stage we employed regression analysis, which exposes relations between the characteristics and enables computation of indices from other ones through regression equations. Correlation between total phosphorus content in the water of Karelian lakes and the zooplankton biomass was studied (Fig.). The linear regression equation was calculated, where both coefficients had a reliable value $(\mathrm{p}<0.05)$ :

$$
\text { LOG }(\text { Bzpl })=(0.877 \pm 0.116) * \text { LOG }(\text { Ptot })-(1.254 \pm 0.149),
$$

where: Bzpl - zooplankton biomass, $\mathrm{g} / \mathrm{m}^{3}$; Ptot - total phosphorus content, $\mu \mathrm{g} / \mathrm{l}$.

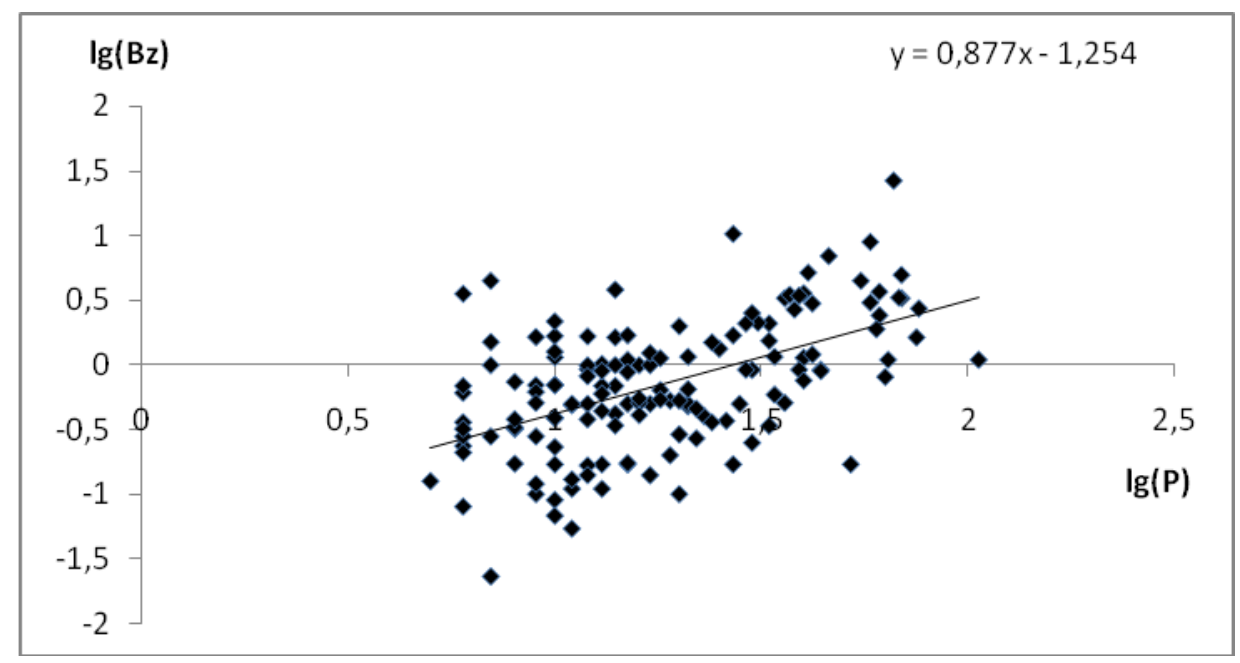

Fig. Dependence of zooplankton biomass values on total phosphorus values (both in logarithmic form); $\lg (\mathbf{P})$ - the logarithm of the concentration of the total phosphorous in the water $(\mu \mathrm{g} / \mathrm{l}) ; \lg (\mathrm{Bz})$ - the logarithm of the zooplankton biomass $\left(\mathrm{g} / \mathrm{m}^{3}\right)$

Prognostic values of zooplankton biomass were calculated from different total phosphorus values corresponding to the lake status: $10 \mu \mathrm{g} / 1$ - oligotrophic; $20 \mu \mathrm{g} / 1$ - mesotrophic; $30 \mu \mathrm{g} / 1$ - transitional between meso- and eutrophic; $50 \mu \mathrm{g} / 1$ - eutrophic type. Estimates of mean values of the indices, as well as confidence limits for $95 \%$ probability are shown in Table 1.

Table 1.

Values of zooplankton biomass calculated from total phosphorus concentration

\begin{tabular}{|c|c|c|c|}
\hline $\begin{array}{c}\text { Total phosphorus } \\
\text { concentration, } \boldsymbol{\mu g} / \mathbf{l}\end{array}$ & \multicolumn{3}{|c|}{ Zooplankton biomass, g/m } \\
\hline & mean & $\begin{array}{c}\text { left-hand } \\
\text { confidence limit }\end{array}$ & $\begin{array}{c}\text { right-hand confidence } \\
\text { limit }\end{array}$ \\
\hline 10 & 0.420 & 0.126 & 1.406 \\
\hline 20 & 0.772 & 0.197 & 3.027 \\
\hline 30 & 1.102 & 0.256 & 4.741 \\
\hline 50 & 1.726 & 0.357 & 8.343 \\
\hline
\end{tabular}

You can see the calculated values do not properly reflect the status of zooplankton communities at different phosphorus concentrations in the water. E.g., when phosphorus 
concentration is $10 \mu \mathrm{g} / 1$ mean prognostic values of the biomass $\left(0.42 \mathrm{~g} / \mathrm{m}^{3}\right)$ correspond to low nutrient content, i.e. reflect the oligotrophic status of the lake. The confidence interval however comprises a range of zooplankton biomass values - from the oligotrophic to the $\alpha$ mesotrophic (0.126-1.406). The forecast becomes less accurate as the phosphorus concentration increases.

The low accuracy of zooplankton biomass values forecasted using total phosphorus content in the water is due to some features of regression analysis. Calculations by regression equation can yield only mean values of the sought index (function) for a specific value of the independent variable. When input data are highly variable the dispersion of the indices and the regression coefficient error increase, wherefore the forecast accuracy (scattering of values within the confidence interval) decreases. This is the situation observed when regression analysis is applied to the data set on lakes of Karelia. Although regression coefficients in the relation between hydrobiological indices and phosphorus content in the water are reliable, zooplankton biomass is quite variable, which makes its accurate forecast based on phosphorus concentration in the water impossible.

Since the distribution of traits in the data set of lakes of Karelia features distinct asymmetry (values typical of low-productivity lakes prevail), one may presume that in the forecast of values of the traits sought not all of them would have equal probability of manifestation for the given value of the independent variable from available data. A differentiated approach is needed for the different statistical significance of the input data to be taken into account, i.e. the whole range of values should be split into gradations and the algorithm should be developed to reconstruct the missing data for each specific gradation. This approach would notably enhance the accuracy of the forecast.

The approach can be implemented through contingency tables [5]. To build contingency tables one should perform the procedure of indexing the waterbodies in question. We developed two indexes based on the following groups of parameters: hydrochemical index $\left(\mathrm{HCh}_{\text {troph }}\right)$ - from the values of total phosphorus, total nitrogen, suspended matter, chlorophyll "a"; and hydrobiological index (HB) - from zooplankton and zoobenthos biomass values. These parameters were chosen because of reliable correlation detected between them (their values in logarithmic form).

The indexes for each group of parameters were determined through cluster analysis, which brings several traits down to one - the generalized measure of distance between each pair or a greater number of study objects. The objects were combined into three groups by the distance (Euclidean measure) and each group was assigned an index - a number from 1 to 3, with the parameters in the series increasing.

The next step was to analyze the table of contingency between the hydrochemical $\left(\mathrm{HCh}_{\text {troph }}\right)$ and the hydrobiological (HB) indexes (Tab. 2).

According to the $\chi^{2}$ test value $(25.7)$, the two indexes are confidently $(p<0.05)$ related. Hence, independent assessments of the lakes (their indexing) by hydrochemical and by hydrobiological parameters coincide. Indeed, the first gradation of the hydrochemical index $\mathrm{HCh}_{\text {troph }}$ comprises a greater number of lakes (22 out of 44) also falling into the first gradation by the hydrobiological index HB (15 from the second HB gradation, 7 - from the third one). Correlation between hydrochemical and hydrobiological parameters is manifest also within the second $\mathrm{HCh}_{\text {troph }}$ gradation. Thus, most lakes (21 out of 40 ) fit into the second gradation by the $\mathrm{HCh}_{\text {troph }}$ and $\mathrm{HB}$ indexes. A similar conformant pattern is observed for lakes of the third gradation by the $\mathrm{HCh}_{\text {troph }}$ index. It contains no lakes falling into the first gradation by the $\mathrm{HB}$ index, 12 out of 26 lakes of the second HB gradation, and 14 - of the third HB gradation.

Thus, the contingency table reflects the regular relationship between the indexes based on the change in the concentration of nutrients (mainly phosphorus) in the water and the corresponding increase in the lakes' zooplankton and zoobenthos production. Since the 
indexes are confidently related, one group of parameters can be forecasted relying on the other one.

Table 2.

Contingency table based on lake gradation by hydrochemical (lines) and hydrobiological (columns) indexes

\begin{tabular}{|c|c|c|c|c|}
\hline $\begin{array}{c}\text { Line gradation - trophicity } \\
\text { classes by the } \mathbf{H C h}_{\text {troph }} \text { index }\end{array}$ & \multicolumn{3}{|c|}{ Column gradation - trophicity classes by the } & \multirow{2}{*}{ Line total } \\
\hline & 1 & 2 & 3 & \\
\hline 1 & 22 & 15 & 7 & 44 \\
\hline 2 & 12 & 21 & 7 & 40 \\
\hline 3 & 0 & 12 & 14 & 26 \\
\hline Column total & 34 & 48 & 28 & 110 \\
\hline
\end{tabular}

Zooplankton biomass was forecasted using total phosphorus content in the water. The forecast accuracy ranged for different gradations within 55-86\% (the accuracy averaged for the whole lake sample set was 66\%). Accuracy was the highest (86\%) for the third gradation of lakes with the highest phosphorus content in the water. This fact proves the sample set under analysis contains a distinct group of lakes with elevated trophicity. Stability of the lakes' parameters and high correlation between them ensured the highest accuracy of the forecast. On the other hand, the forecast accuracy for lakes of gradations $1 \& 2$ is lower $-55-56 \%$. The reason for that is the group of "transitional" lakes. Because of their variable status, correlations between hydrobiological and hydrochemical parameters there are fuzzier. The accuracy of zoobenthos forecast by total phosphorus content in the water was $71-78 \%$ (the accuracy averaged for the whole sample set was 74\%).

\section{Summary}

Analysis of data on lakes of Karelia has shown oligo-mesotrophic lakes prevail in the sample set under study, whereas eutrophic lakes are rather few. Regression analysis did not enable reconstruction of hydrobiological data because of their high variability. We therefore developed integrated hydrochemical and hydrobiological indexes reflecting the trophic status of the lakes. Multivariate statistics and information analysis methods were employed to trace correlations between the hydrochemical and hydrobiological indexes. Predictive tables and keys were computed to enable reconstruction of data on zooplankton and zoobenthos biomass relying on data on total phosphorus content in the lake water. The accuracy of reconstruction of the hydrobiological data ranges within $55-86 \%$.

\section{References}

1. Ivanter, E V., Korosov, A.V. The introduction to the quantitative biology. Petrozavodsk: PetrSU, 2003, 304 p. (in Russian).

2. Menshutkin, V.V. Skills of Modeling (ecology, physiology, evolution). Petrozavodsk-Sankt-Petersburg: KRS RAC, 2010, 419 p. (in Russian).

3. Pusachenko, Yu.G. The mathematical methods in ecological and geographical investigations. Moscow: Academia, 2004, 416 p. (in Russian).

4. Rosenberg, G.S., Saksonov, S.V., Kostina, N.V., Kudinova, G.E. The assessment of the state and approaches to the control of bioresources of Middle and Low Volga // The Fundamental Approaches to Management of Bioresources. Moscow: KMK, 2005, p. 351-360 (in Russian).

5. Shitikov, V.K., Rosenberg, G.S., Zinchenko, T.D. The quantitative hydroecology (methods, criteria, decisions). Book 2. Moscow: Nauka, 2005, 337 p. (in Russian).

6. The State of the Water Bodies of the Republic of Karelia. Petrozavodsk: Karelian Research Center of RAS, 2007, 210 p. (in Russian). 